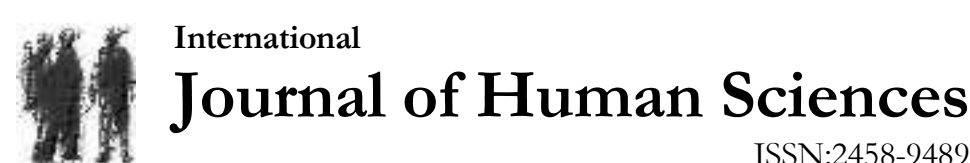

Volume 17 Issue 3 Year: 2020

\section{Attitudes of surgical nurses toward postoperative opioid use: A qualitative study ${ }^{1}$}

\author{
Sevim Şen ${ }^{2}$ \\ Esra Usta ${ }^{3}$ \\ Dilek Aygin ${ }^{4}$
}

\begin{abstract}
Aim: This study was aimed to investigate the attitudes of surgical nurses toward postoperative opioid use.

Method: The descriptive phenomenological study consists of 30 surgical nurses in two hospitals in Turkey. Data were collected by semi-structured face to face interviews. Data analyses were done by qualitative theme analysis.

Findings: As a result of the theme analysis, six themes related to surgical nurses' attitudes of postoperative opioid analgesic use were identified. These themes are named as follows: primary indications for opioids, safest route for opioid administration, complications observed following opioid administration, opioid addiction, opioid safety, feeling stressed while administrating opioids. Nurses (13/30) stated that intravenous way is safer as it affects fast, and it is easy to control; while 12 nurses said that intramuscular application is safer as there are few possibilities for complications. While all of the nurses were agreed on that opioids are addictive, eighteen of them think that opioid drugs are safe, and 16 stated that administering opioids did not create stress.

Conclusions: Nurses face some obstacles related to the use of opioids in the process of pain management, such as the abuse of opioids and encountering side effects. Pain management and opioid use should be given a great place in nursing education.
\end{abstract}

Keywords: Opioid; attitude of health personnel; pain management; nurses.

\footnotetext{
1 The study was presented as a poster at the 9th National Turkish Surgical and Operating Theater Nursing Congress, Muğla/Turkey, 12-15 November 2015.

2 Asst. Prof. Dr., Kahramanmaraş Sütçü İmam University, Afşin School of Health, Department of Nursing, sevimsen@ksu.edu.tr (D) Orcid ID: 0000-0002-8430-193X

3 Dr., Lecturer, Düzce University, Vocational School of Health Services, esrakilliklioglu@gmail.com (iD) Orcid ID: 0000-0002-1135-6526

4 Prof. Dr., Sakarya University, Faculty of Health Sciences, Department of Nursing, daygin@,sakarya.edu.tr (iD) Orcid ID: 0000-0003-4620-3412
} 
Şen, S., Usta, E., \& Aygin, D. (2020). Attitudes of surgical nurses toward postoperative opioid use: A qualitative study. Journal of Human Sciences, 17(3), 911-920. doi:10.14687/jhs.v17i3.5977

\section{Introduction}

According to the International Association for the Study of Pain (IASP), pain is defined as "An unpleasant sensory and emotional experience associated with actual or potential tissue damage or described in terms of such damage" (IASP, 1979). Surgical pain is an acute pain which starts with a surgical trauma and decreases over time by tissue healing. However, it may continue as a chronic pain. Surgical pain is considered as an iatrogenic phenomenon as it is related to tissue and nerve damage. Pain can arise from cutaneous, deep somatic or visceral structures. Surgery is typically followed by acute pain and patients frequently experience different types of pain. The type of pain may occur as somatic, visceral or neuropathic (Corke, 2013; Misiołek vd., 2014).

Opioids have been known as the oldest and the most powerful analgesics for years. Morphine is particularly the most commonly used opioid for the management of pain related to severe trauma, and intravenous administration should be preferred instead of intramuscular administration to protect tissue perfusion in traumatized patients. Nausea, vomiting, constipation, sedation, urinary retention, itching, mucositis and decreased blood pressure and respiratory depression at high doses are the most common side effects of opioids, which nurses should carefully observe (Harsoor, 2011; Meissner vd., 2015; Misiołek vd., 2014; Wels, 2012).

Production and consumption of opioids are controlled internationally. According to the findings of the Pain \& Policy Studies Group of the University of Wisconsin, opioid consumption rates are $750 \mathrm{mg} /$ person in the United States, $427 \mathrm{mg} /$ person in Denmark, $274 \mathrm{mg} /$ person in Spain, $211 \mathrm{mg} /$ person in France, and $12 \mathrm{mg} /$ person in Turkey. In the 2012 study of the Pain \& Policy Studies Group of the University of Wisconsin, Turkey ranked the 87th in opioid use $(0.7815$ $\mathrm{mg} /$ person) among 158 countries. These lower rates observed in Turkey can be explained by rigid protocols to obtain opioids and the lack of medicine consumption. Nurses closely monitor pain treatment on condition that they apply medication in pain management and assess the results of the application. When opioid analgesics get involved in pain management, it is nurse's responsibility to diagnose the patient's pain, to provide and store opioid medication, to apply it with sufficient doses and intervals, and to monitor the process, which are critical steps. Therefore, it is important to determine situations that prevent nurses, who have a key role in pain management, from maintaining effective opioid treatment. In the light of this information, this study was carried out in order to determine the nursing dimension of inadequate opioid use. (Alexander, 2016; Cowan, Wilson-Barnett, Griffiths and Allan, 2003; Eti Aslan, 2011; Gardiner vd., 2012; Pain \& Policy Study Groups, 2015).

\section{Purpose}

This study was aimed to investigate the attitudes of surgical nurses toward postoperative opioid use.

\section{Method and Material}

\subsection{Study design}

The study was designed as a descriptive phenomenological study as it allows a thorough investigation of the factors affecting the attitudes of surgical nurses toward postoperative opioid use from a systematical, behavioral, and ethical perspective (Christensen, Welch and Barr, 2017).

\subsection{The population of the study and sample}

The study population consisted of 96 nurses working at surgery clinics in two state hospitals in Turkey. These two cities were selected for sampling as the researchers were residents of these cities. Data were collected until saturation was achieved without taking sample size into consideration and the study was finished with 30 surgical nurses $(31.25 \%$ of the participants) who volunteered to participate in the study. The fact that the nurses have been working in the surgical clinic for at least one year was determined as the inclusion criteria. (Gentles, Charles, Poeg and Mckibbon, 2015). 
Șen, S., Usta, E., \& Aygin, D. (2020). Attitudes of surgical nurses toward postoperative opioid use: A qualitative study. Journal of Human Sciences, 17(3), 911-920. doi:10.14687/jhs.v17i3.5977

\subsection{Data collection}

The study data were collected through the socio-demographic question form and the semistructured interview form. Voice recordings were made during the interviews. The sociodemographic question form was developed by the researchers. The form consisted of eight items investigating nurses' age, their sex, marital status, educational level, total period of experience in the profession, experience in the surgical clinic, education about pain management, and education about opioid use. In line with literature knowledge, the semi-structured interview form was prepared by the researchers to determine the nurses' attitudes towards post-operative opioid use (McCaffery et al 2000; Voshall et al 2013;Wels 2012). The form consists of 7 items. These are:

- In which patients the opioid analgesics are used, the situation in which the surgical nurses use these analgesics in their clinics (which patient groups/surgical interventions)

- When applying opioid analgesics, what the safest route is, which route is used frequently in their clinics

- Self-opioid use among surgical nurses

- Experiences of complications related to opioid use during clinical practice, if yes; how they are managed

- Whether opioid drugs are addictive, and experiences of opioid addiction during clinical practice

- How the nurses are affected emotionally by the administration of opioids

- Whether opioid drug administration is safe

The study was carried out between February and May, 2015. After the necessary permissions were obtained from the hospital administrations, in-depth individual interviews were performed with nurses who were informed about the aim and duration of the study and who gave their written consent to take part in the study. The interviews were performed in a special room in the hospital within 40-60 min in line with a semi-structured interview form. The interview process was carried out by listening actively using questions. Voice recordings were made by the researcher during the interview.

\subsection{Data analysis}

Strauss and Corbin suggest two different data analyses (descriptive analysis and content analysis) for the analysis of qualitative data (Corbin and Strauss, 2008). Theme analysis was used for the data obtained through interviews in this study. The notes and sound files recorded by the researchers were listened at the end of the interview and interviews were transcribed verbatim. The report compiled was read by all the researchers twice and grouped relevantly. The principles and habits of surgical nurses about opioid drug use were elaborated on. Data analyses were carried out by taking into consideration the similarities and differences of behaviors and attitudes in written interview forms produced when all the interview recordings were completed. Initially the data were encoded in order to achieve content integrity. The researchers gathered together, and descriptive codes were compared. The data were reduced, organized and merged together. Themes were formulated from categories consisting of grouped codes. The data were organized and defined according to codes and themes. Finally, the findings were interpreted. Assessment was carried out in this study by determining six headings (themes). The study included statements that best emphasized/defined surgical nurses' principles and habits of opioid drug use in line with these themes.

\subsection{Ethical Considerations}

Written permissions were obtained from the hospital administrations. In addition, the objective of the study was explained to the participants and -their voluntary participation was solicited. The participants were informed that voice recordings would be taken during the interview, the recording and its documented form would be sent to them. Moreover, they were told that these recordings would be included in the analysis provided they gave their consent and no 
Şen, S., Usta, E., \& Aygin, D. (2020). Attitudes of surgical nurses toward postoperative opioid use: A qualitative study. Journal of Human Sciences, 17(3), 911-920. doi:10.14687/jhs.v17i3.5977

personal information would be shared with third-party persons, and their written permissions were obtained.

\subsection{Limitations of the study}

Phenomenology research may not produce precise and generalizable results in accordance with the nature of qualitative research. However, it can provide examples, explanations and experiences that will provide results that will help us better recognize and understand a case. The biggest limitation for this study is that generalization was not possible and the sample was limited to nurses working at surgical clinics.

\section{Results}

The age distribution was found to be $30 \pm 5.27$ ( $\min -\max =22-42)$, and the sample consisted of $90 \%(n=27)$ females. Sixty-three point three percent $(n=19)$ of the nurses were married and $73.3 \%(\mathrm{n}=22)$ had a bachelor's degree in nursing. The average year in the profession was found to be $8.27 \pm 4.7$ ( $\min -\max =1-16)$ years, while the average working period in a surgical unit was $5.23 \pm 3.4(\min -\max =1-15)$ years. $30 \%(\mathrm{n}=9)$ of the sample had a pain experience before, and $33.3 \%$ $(\mathrm{n}=10)$ had a formation related to opioid use (up to 6 hours) (Table 1).

Table 1. Socio-demographic characteristics of the nurses

\begin{tabular}{|c|c|c|}
\hline Characteristics & $\mathbf{n}$ & $\%$ \\
\hline $\begin{array}{l}\text { Gender } \\
\text { Female } \\
\text { Male }\end{array}$ & $\begin{array}{c}27 \\
3\end{array}$ & $\begin{array}{l}90 \\
10\end{array}$ \\
\hline $\begin{array}{l}\text { Marital Status } \\
\text { Single } \\
\text { Married }\end{array}$ & $\begin{array}{l}21 \\
19\end{array}$ & $\begin{array}{l}36.7 \\
63.3 \\
\end{array}$ \\
\hline $\begin{array}{l}\text { Educational Level } \\
\text { Vocational Health School / Associate degree } \\
\text { Bachelor Degree } \\
\text { Master / Doctorate }\end{array}$ & $\begin{array}{c}5 \\
22 \\
3 \\
\end{array}$ & $\begin{array}{c}16.7 \\
73.3 \\
10 \\
\end{array}$ \\
\hline $\begin{array}{l}\text { Education on Pain Management } \\
\text { Education on Opioid Analgesic Use }\end{array}$ & $\begin{array}{c}9 \\
10\end{array}$ & $\begin{array}{c}30 \\
33.3 \\
\end{array}$ \\
\hline Age, years (mean \pm SD) & \multicolumn{2}{|c|}{$30 \pm 5.27$} \\
\hline Experience in the Profession, years (mean \pm SD) & \multicolumn{2}{|c|}{$8.27 \pm 4.7$} \\
\hline Experience in Surgical Clinic, years (mean \pm SD) & \multicolumn{2}{|c|}{$5.23 \pm 3.4$} \\
\hline
\end{tabular}

mean $\pm S D:$ mean土standard deviation

As a result of the theme analysis, six themes related to surgical nurses' attitudes of postoperative opioid analgesic use were identified. These themes are named as follows: primary indications for opioids, safest route for opioid administration, complications observed following opioid administration, opioid addiction, opioid safety, feeling stressed while administrating opioids.

\section{Primary indications for opioids}

Nurses stated that opioid analgesics should primarily be used in major surgeries $(16 / 30)$, in postoperative period (11/30), terminal phase of an illness $(9 / 30)$, and in oncology patients $(8 / 30)$. In their clinics, opioid analgesics were used for postoperative pain (16/30), oncology patients and terminally ill patients $(11 / 30)$. Four nurses explained these experiences as follows: 
Şen, S., Usta, E., \& Aygin, D. (2020). Attitudes of surgical nurses toward postoperative opioid use: A qualitative study. Journal of Human Sciences, 17(3), 911-920. doi:10.14687/jhs.v17i3.5977

"Paracetamol or NSAIDs (nonsteroidal anti-inflammatory drugs) should be used for all types of pain, which is hard to manage."

"(Opioids) should be used for terminally ill patients, for the management of postoperative pain after major surgeries, and for oncology patients."

"In our clinic, we give opioids as if giving a candy for the treatment of postoperative pain. When the patients have kidney stones, we can't use NS AIDs; therefore, we prefer opioid analgesics."

"In the clinic, it is (opioids) used for oncology patients, terminally ill patients, and major surgery patients."

\section{Safest route for opioid administration}

Among the nurses, 13 reported that intravenous (IV) or intramuscular (IM) administration were both safe; however, 24 used intravenous administration in their clinic. Fourteen of the nurses stated that IV administration was safer as it is a fast-affecting mode of administration and it is easy to control, while 12 said that intramuscular application was safer as there are few possibilities for complications. Three nurses explained these experiences as follows:

"We prefer intravenous administration as it is preferred because of its short effect time. This way is safer when it is administrated correctly."

"We prefer intravenous administration. As it helps us give the medication to the patient in a controlled way, intravenous administration is safer."

"Intramuscular administration is safer because intravenous administration causes bypotension. Also, I think these kinds of medication should be given by patient-controlled analgesia. It avoids giving more than one medication at the same time, and also the patient knows that s/ he has control of taking analgesic and feels more comfortable. In the clinic, intramuscular and intravenous administrations are used equally."

\section{Complications observed following opioid administration}

Among the nurses, 21 did not observe any complications related to opioid administration during clinical practice, the other 9 said that the opioid-related complications were hypotension $(10 / 30)$, vomiting (7/30), respiratory arrest (7/30), bradycardia $(3 / 30)$, and loss of vision $(3 / 30)$. Five nurses explained these experiences as follows:

"Yes, there was a complication because of these medications. These medications lower blood pressure. Even when it is prepared without calculating the doses $1 \mathrm{mg}$ per kilo, there are more complications. Once, $100 \mathrm{mg}$ Pethidine was ordered to my thin female patient and even though I administered intramuscular $50 \mathrm{mg}$ Pethidine, the patient had nausea, vomiting, and ballucinations. When the patient had her conscience back, she complained to me saying "What did you do to me? I was dying!" Later on, we gave her IV fluid and took the situation under control."

"In the intensive care unit, respiratory arrest occurred after Pethidine. (The patient) needed to be intubated again."

"After the delivery, Pethidine was ordered by the doctor and even if I administered it as an infusion inside $100 \mathrm{ml}$ saline solution, loss of sight occurred. The patient was able to recover hardly in one day, and we needed to do close follow-up."

"One of my patients had hypotension-related syncope. The patient was closely followed up."

"Bradycardia occurred; infusion was stopped immediately, and the patient was followed up."

\section{Opioid addiction}

All the surgical nurses in the study were thinking that opioids were addictive, while 7 of them stated that they had patients or colleagues who were addicted to opioids. The opinions of 2 participants on this issue are as follows:

"Yes, (opioids) are addictive. For example, I have a patient like this in my clinic now who has been hospitalized for three months and almost every day he/she has received Pethidine. After reducing the doses in the last two weeks, the patient still has withdrawal symptoms."

"It is addictive. There is a man with pain always coming to the emergency department. One day he came during my ambulance night shift and the doctor ordered Diclofenac Sodium. While I was preparing the medication, the patient came closer to me to check the name of the medication and told me to prepare Pethidine for him. Also, I had another patient from the orthopedics clinic who was addicted to Petbidine and he always asked for Pethidine. I 
Şen, S., Usta, E., \& Aygin, D. (2020). Attitudes of surgical nurses toward postoperative opioid use: A qualitative study. Journal of Human Sciences, 17(3), 911-920. doi:10.14687/jhs.v17i3.5977

told him 'I will not give you this medication; you are very young, and this medication has started to make you addicted to it. One day you will be an addict like the ones who use heroin and ruin your life. Make a complaint about me if you want, but I am not going to give you this medication. I am closing the door; the window is just there, you can jump from there". I think my speech made bim think. Two days later be was discharged from the hospital and a couple of days later he came back to the hospital to thank me for not giving the medication that day."

\section{Opioid safety}

Eighteen of the nurses think that opioid drugs are safe and 12 of them think that they are not. Here there are two opposite opinions about the safety of opioid use:

"Opioids are safe medications if the dose and the duration of use are calculated carefully. For example, when the patient is hospitalized, he/ she receives opioids for some days. Let's say that the patient has been in the hospital for five days and they are discharging him/her with the prescription of Paracetamol. It shouldn't work like this; the analgesic given on post-operative first day can be a strong one, but then the doses should be decreased slowly."

"Of course, they are not (safe). Besides, they cause addiction. A patient with addiction can do anything. The risk of complication is very high. Therefore, when I go to patient rooms, I think of administering opioids in an intravenous or intramuscular way. I need to control many times before administering opioids. Also, the storage conditions are very important. The drawers of these medications should not be in an open area, it should be opened with the observation of another person, it should be checked, and the medications should be counted. No person should be able to reach the medications alone. We hear and know lots of things, that's why we have that much concerns and rigorous behaviors."

\section{Feeling stressed while administrating opioids}

Among the nurses, 16 stated that administering opioids did not create stress on themselves. However, the number of nurses who experienced anxiety and stress should not be underestimated. Here, there are two important opinions from nurses who reported stress:

"It is stressing me. Never I have liked these kinds of medications. There are many negative effects such as hypotension or lightheaded feeling; and I have never used them for myself either. When the doctors tell me to administer Pethidine to a patient, I warn them to administer Tramadol first."

'Yes, I really don't like to administer these medications. I don't like Petbidine in particular because it is not clear what is going to happen later. We use Pethidine less frequently than in the past, but I still have a doubt in my mind as if respiratory arrest develops. But when I need to use Pethidine, I always check patient's vital signs before the administration and follow up closely for one hour."

\section{Discussion}

The quality of pain management is related to the knowledge, attitudes and skills of health professionals. At this point, nurses have a key role in pain management by evaluating pain, joining the treatment process and observing the outcomes of the treatment (Gardiner vd., 2012; de Rond vd., 2000; Edwards vd., 2001; Eid, Manias, Bucknall and Almazrooa, 2014; McCaffery, Ferrell and Pasero, 2000; Taylor and Stanbury, 2009). This study was conducted to determine the attitudes of surgical nurses to use opioids in postoperative pain management. For the success of pain management, increasing the level of knowledge about medication administration and decreasing the level of stress related to unknowns. For overcoming obstacles in opioid use, a clear definition of these obstacles is essential.

In this study, it can be seen that the average age of the nurses is $30 \pm 5.27$ and they have $8.27 \pm 4.7$ years of clinical practice, which shows us that the nurses in the sample had considerable experience in patient care and treatment. Only 9 of the nurses had an education program about pain management after graduation. It can be seen that our sample had clinical experience; however, they did not have adequate postgraduate education related to pain management. Unfortunately, there are numerous studies showing that healthcare workers need more knowledge about pain management, yet topics about pain management are not explained well in higher education 
Şen, S., Usta, E., \& Aygin, D. (2020). Attitudes of surgical nurses toward postoperative opioid use: A qualitative study. Journal of Human Sciences, 17(3), 911-920. doi:10.14687/jhs.v17i3.5977

(Bookbinder vd., 1996; Clarke, French, Bilodeau, Capasso, Edwards and Empoliti, 1996; Edwards vd., 2001; Eid vd., 2014; Gardiner vd., 2012; Morgan, 2014; Plaisance and Logan, 2006; Taylor and Stanbury, 2009; Voshall, Dunn and Shelestak, 2013). On the other hand, there are also important literature findings showing a positive correlation between the success of pain management and nurses' characteristics such as age, education level, professional experience, and level of knowledge related to pain management (Clarke vd., 1996; Edwards vd., 2001; Eid vd., 2014; McCaffrey and Ferrell, 1997; Morgan, 2014). Although the nurses' level of knowledge in pain management was not investigated in the study, it was thought that only in these interviews about the nurses' approaches to opioid use after surgery, there might be a lack of knowledge about the use procedures of opioids.

Regarding the questions about the need of using opioid analgesics, the answers given show that the nurses clearly know the importance of opioids in pain management. It is possible to see that opioids are mostly used in the management of severe pain in the clinical area. In addition, some nurses stated that they administered opioids very frequently unless no overuse of opioids was observed in the records, which may show that there is a perception of opioid overuse. This is an indication that nurses have inadequacy in pain management as well. It is seen that the number of nurses who stated that painkillers are given in excessive amounts in the clinics is low in the related studies in the literature (Taylor and Stanbury, 2009). At this point, the concept of necessity is to be defined well and this concept takes us to the assessment of pain. It has been asserted in various studies that nurses do not have adequate knowledge in pain management and they may make errors in pain assessment with the worry of tolerance development and probability of addiction (Bookbinder vd., 1996; Gardiner vd., 2012; Edwards vd., 2001; Eid vd., 2014; Smith and Bruckenthal, 2010; Taylor and Stanbury, 2009; Voshall vd., 2013).

Most of the nurses stated that they did not experience any complications related to opioids. On the other hand, the complications experienced by 9 of the nurses included hypotension, vomiting, respiratory arrest, bradycardia, and loss of sight. In the literature, there is a different range of percentages of opioid-related complications, such as nausea-vomiting, constipation, respiratory depression, hypotension, urinary retention, itching, and mucositis (Alexander, 2016; Good, 1998; Harsoor, 2011; Meissner vd., 2015; Misiołek vd., 2014; Wels, 2012). The side effects of these medications may create attitude changes among the nurses. Good (1998) emphasized the Middle Range Theory for pain management and stated that the effects and side effects of medications are effective factors on the attitude towards administering medications. Besides, there are important literature findings showing that doctors and nurses tend to use less analgesic because of the concerns regarding the possible side effects (De Rond, de Wit, van Dam and Muller, 2010; Gardiner vd., 2012; Green and Tait, 2002; Jho vd., 2014; Krokmyrdal and Andenæs, 2015; Kuhn, Cooke, Collins, Jones and Mucklow, 1990; Owen, McMillan and Rogowski, 1990; Voshall vd., 2013). Patients and their relatives have also concerns regarding to opioid use; therefore, nurses should understand these concerns and try to communicate with them in order to relieve these concerns. To maintain a healthy communication, the nurse is supposed to have enough knowledge about pain management (Gardiner vd., 2012).

All the nurses stated that opioids are addictive and 7 of them said that they had patients or colleagues who were addicted to an opioid. According the report of American Society of Addiction Medicine (ASAM) in 2014, 4.3 million people reported nonmedical use of prescription opioids. Addiction is a chronic disease; however, it can be managed. In accordance with the ASAM statement, addiction disorders may occur due to psychosocial and environmental factors (Alexander, 2016; Good, 1998; Krokmyrdal and Andenæs, 2015). It is reported in the literature that drug abuse in Turkish health professionals is similar to the general society (Yargıç, 2009). In studies carried out in different cultures, it has been emphasized that the rates of drug abuse among anesthetists and anesthesia nurses are high (Wright et al., 2012). In Turkey, there are also case presentations related to drug abuse observed among physicians, nurses, and anesthetists that cannot be treated and even result in death (Bozdağ, Şamdanc1, Şahin, Aydın and Sayın, 2013; Büyük, Üzün, Koçak and Özer, 2005; Yarg1ç, 2009). In this study, it can be seen that opioids are considered as 
Şen, S., Usta, E., \& Aygin, D. (2020). Attitudes of surgical nurses toward postoperative opioid use: A qualitative study. Journal of Human Sciences, 17(3), 911-920. doi:10.14687/jhs.v17i3.5977

risky medications and there are concerns in terms of opioid administration. Furthermore, approximately half of the nurses experienced stress while administrating opioids. The nurses in the sample have had long years of professional experience, which is sufficient to be able to manage physical and emotional effects of stress during opioid administration. However, lack of knowledge about the necessity of opioid use and the concerns related to opioids lead nurses to manipulate the prescriptions of doctors, such as decreasing the dose or changing the administration frequency. All these factors may bring about serious errors with the administration of medications. It is thought that concerns regarding this topic can be overcome through intensive education and sharing of experiences. The education program must include the information related to the selection criteria of medications, and the information that opioid addiction is a manageable process if encountered in any patient. Furthermore, it must be determined which way will be followed in which circumstance with protocols in medication requests that are applicable in case of necessity" in order to minimize medication administration errors arising from worries.

Twelve of the nurses think opioid drugs are not safe. Besides, they also indicated that the patients might need opioids after surgery and some of them would come back to the clinic to ask for more opioids. The literature also shows that nurses have negative attitudes towards administration of opioids because of opioid use without medical reasons (Krokmyrdal and Andenæs, 2015; McCaffrey and Ferrell, 1997; Voshall vd., 2013). It was seen that when asked about the most common way for opioid administration, certain nurses stated that they considered the intramuscular administration to be safe because of its slow absorption, while certain nurses preferred intravenous administration to be able to stop the infusion when needed. The common opinion is that the medication should be administered slowly and under close control. It is remarkable that nurses only take into consideration usage when they regard opioids as safe or unsafe medication. Nevertheless, the reports of institutions that deal with issues like patient safety or medication safety emphasize that it must be determined in clinics which medication will be administered to which patient in which dose and manner, that the team approach and communication is important in pain management, and that opioids can be used safely by establishing pain management gaps (Food \& Drug Administration; 2017; Krokmyrdal and Andenæs, 2015; The Joint Comission, 2012). However, the fact that such protocols have not been formulated in institutions in which nurses are employed and the worries that the nurses experience as a result of their inadequate knowledge result in their negative attitudes towards opioid use. The study results show similarities to other studies in the literature in terms of the negative attitude (Alexander, 2016; Good, 1998; McCaffrey and Ferrell, 1997; Krokmyrdal and Andenæs, 2015; Voshall vd., 2013).

\section{Conclusions and Recommendations}

Nurses have considerable concerns regarding the side effects of opioids and these concerns are related to various experiences of opioid use. On the other hand, false expressions and intentions of addicted patients for asking more opioids can be easily understood by experienced nurses. It can be seen that even the experienced nurses try to manipulate the prescriptions of doctors and also have concerns while administering these medications. One of the main reasons of this result is that the sample in the present study worked in clinics in which there were no procedures for safe opioid selection and all the side effects are generalized for all types of opioids. It is thought that an effective education plan for nurses and experience sharing among nurses may help to improve the selection of correct opioid for pain management. Since it has been seen that the lack of knowledge cause anxiety, disturbance during opioid administration, and the intention of manipulating the prescriptions among nurses, eliminating the lack of knowledge related to opioid use may help to provide medication safety and good pain management; therefore, the quality of patient care can be increased. 
Șen, S., Usta, E., \& Aygin, D. (2020). Attitudes of surgical nurses toward postoperative opioid use: A qualitative study. Journal of Human Sciences, 17(3), 911-920. doi:10.14687/jhs.v17i3.5977

\section{References}

Alexander, S. A. (2016). Project to improve nurses' knowledge of, and attitudes towards, pain management at end of life. Dissertion. University of Massachuses Amherst, Massachuses.

Bookbinder, M., Coyle, N., Kiss, M., Goldstein, M.L., Holritz, K., Thaler, H., ... Portenoy, R.K. (1996). Implementing national standards for cancer pain management: program model and evaluation. Journal of Pain and Symptom Management, 12(6), 334-347.

Bozdağ, Z., Şamdanc1, E.T., Şahin, N., Aydın, NE, Sayın, S. (2013). Pethidine related sudden death. Journal of Forensic Medicine, 27(1), 75-79.

Büyük, Y., Üzün, İ., Koçak, U., Özer, E. (2005). Sudden death of a health worker due to pethidine abuse: a case report. Journal of Forensic Medicine, 19(1), 33-36

Christensen, M., Welch, A., Barr, J. (2017). Husserlian Descriptive Phenomenology: A review of intentionality, reduction and the natural attitude. Journal of Nursing Education and Practice, 7(8), 113-118. doi: 10.5430/jnep.v7n8p113

Clarke, E.B., French, B., Bilodeau, M.L., Capasso, V.C., Edwards, A., Empoliti, J. (1996). Pain management knowledge, attitudes and clinical practice: the impact of nurses' characteristics and education. Journal of Pain and Symptom Management, 11(1), 18-31.

Corbin, J., Strauss, A. (2008). Basics of qualitative research: Techniques and procedures for developing grounded theory (p. 61-74). USA: San Jose State University.

Corke, P. (2013). Postoperative pain management. Australian Prescribe, 36(6), 202-205. doi: 10.18773/austprescr.2013.085

Cowan, D.T., Wilson-Barnett, J., Griffiths, P., Allan, L.G. (2003). A survey of chronic noncancer pain patients prescribed opioid analgesics. Pain Medicine, 4(4), 340-351.

de Rond, M.E., de Wit, R., van Dam, F.S., van Campen, B.T.M., den Hartog, Y.M., Klievink, R.M. (2000). A pain monitoring program for nurses: effects on nurses' pain knowledge and attitude. Journal of Pain and Symptom Management, 19(6), 457-467. doi:10.1016/S08853924(00)00128-7

de Rond, M.E., de Wit, R., van Dam, F.S., Muller, M.J. (2000). A Pain monitoring program for nurses: Effect on the administration of analgesics. Pain, 89(1), 25-38. doi:10.1016/S03043959(00)00344-4

Edwards, H.E., Nash, R.E., Najman, J.M., Yates, P.M., Fentiman, B.J., Dewar, A., ... Skerman, H.M. (2001). Determinants of nurses' intention to administer opioids for pain relief. Nursing \& Health Science, 3(3), 149-159. doi: 10.1046/j.1442-2018.2001.00080.x

Eid, T., Manias, E., Bucknall, T., Almazrooa, A. (2014). Nurses' knowledge and attitudes regarding pain in Saudi Arabia. Pain Management Nursing, 15(4), 25-36. doi: 10.1016/j.pmn.2014.05.014.

Eti Aslan, F. (2011). Ameliyat sonrası bakım. A. Karadakovan \& F. Eti Aslan, In: Dahili ve Cerrahi Hastalkklarda Bakım (p. 107-123). Adana: Nobel Tip Kitabevi.

Food\&Drug Asministration. (2017). Training health care providers on pain management and safe use of opioid analgesics-exploring the forward. 31.10.2017, https://www.fda.gov/drugs/newsevents/ucm538047.htm .

Gardiner, C., Gott, M., Ingleton, C., Hughes, P., Winslow, M., Bennett, M.I. (2012). Attitudes of health care professionals to opioid prescribing in end-of-life care: A qualitative focus group study. Journal of Pain and Symptom Management, 44(2), 206-214. doi:10.1016/j.jpainsymman.2011.09.008

Gentle, S.J., Charles, S., Ploeg, J., Mckibbon, K.A. (2015). Sampling in qualitative research: insights from an overview of the methods literature. The Qualitative Report, 20(11), 1772-1789.

Good, M. (1998). A middle-range theory of acute pain management: Use in research. Nursing Outlook, 46(3), 120-124. doi:10.1016/S0029-6554(98)90038-0

Green, C.R., Tait, A.R. (2002). Attitudes of healthcare professionals regarding different modalities used to manage acute postoperative pain. Acute Pain, 4(1), 15-21. doi:10.1016/S13660071(02)00005-0 
Șen, S., Usta, E., \& Aygin, D. (2020). Attitudes of surgical nurses toward postoperative opioid use: A qualitative study. Journal of Human Sciences, 17(3), 911-920. doi:10.14687/jhs.v17i3.5977

Harsoor, S.S. (2011). Emerging concepts in post-operative pain management. Indian Journal of Anaesthesia, 55(2), 101-103. doi: 10.4103/0019-5049.79872

International Association for the Study of Pain Subcommittee on Taxonomy. (1979). Pain terms: A list with definitions and notes on usage, recommended by the IASP subcommittee on taxonomy. Pain, 6, 249-252.

Jho, H.J., Kim, Y., Kong, K.A., Kim, D.H., Choi, J.Y., Nam, E.J., .. Park, E.J. (2014). Knowledge, practices, and perceived barriers regarding cancer pain management among physicians and nurses in Korea: A nationwide multicenter survey. PLoS One, 9(8): e105900. doi: 10.1371/journal.pone.0105900

Krokmyrdal, K.A., Andenæs, R. (2015). Nurses' competence in pain management in patients with opioid addiction: A cross-sectional survey study. Nurse Education Today, 35(6), 789-794. doi: 10.1016/j.nedt.2015.02.022

Kuhn, S., Cooke, K., Collins, M., Jones, J.M., Mucklow, J.C. (1990). Perceptions of pain relief after surgery. The British Medical Journal, 300(6741): 1687-1690.

McCaffrey, M., Ferrell, B.R. (1997). Nurses' knowledge of pain assessment and management: How much progress have we made?. Journal of Pain and Symptom Management, 14(3), 175-188.

McCaffery, M., Ferrell, B.R., Pasero, C. (2000). Nurses' personal opinions about patients' pain and their effect on recorded assessments and titration of opioid doses. Pain Management Nursing, 1(3), 79-87. doi: 10.1053/jpmn.2000.9295

Meissner, W., Coluzzi, F., Fletcher, D., Huygen, F., Morlion, B., Neugebauer, E., ... Pergolizzi, J. (2015). Improving the management of post-operative acute pain: Priorities for change. Current Medical Research and Opinion, 31(11), 2131-2143. doi: 10.1185/03007995.2015.1092122.

Misiołek, H., Cettler, M., Woroń, J., Wordliczek, J., Dobrogowski, J., Mayzner-Zawadzka, E. (2014). The 2014 guidelines for post-operative pain management. Anaesthesiology Intensive Therapy, 46(4), 221-244. doi: 10.5603/AIT.2014.0041

Morgan, B.D. (2014). Nursing attitudes toward patients with substance use disorders in pain. Pain Management Nursing, 15(1), 165-175. doi: 10.1016/j.pmn.2012.08.004

Owen, H., McMillan, V., Rogowski, D. (1990). Postoperative pain therapy: A survey of patients' expectations and their experiences. Pain, 41(3), 303-307. doi: 10.1016/0304-3959(90)90007Z

Pain and Policy Study Groups. (2015). Global Opioid Consumption. 28.12.2016, http://www.painpolicy.wisc.edu/opioid-consumption-data

Plaisance, L., Logan, C. (2006). Nursing students' knowledge and attitudes regarding pain. Pain Management Nursing, 7(4), 167-175. doi: 10.1016/j.pmn.2006.09.003

Smith, H., Bruckenthal, P. (2010). Implications of opioid analgesia for medically complicated patients. Drugs \& Aging, 27(5), 417-433. doi: 10.2165/11536540-000000000-00000

Taylor, A., Stanbury, L. (2009). A review of postoperative pain management and the challenges. Current Anaesthesia \& Critical Care, 20(4), 188-194. doi:10.1016/j.cacc.2009.02.003

The Joint Comission. (2012). Sentinel event alert, Issue 49: Safe use of opioids in hospitals (p. 1-5).

Voshall, B., Dunn, K.S., Shelestak, D. (2013). Knowledge and attitudes of pain management among nursing faculty. Pain Management Nursing, 14(4), 226-235. doi: 10.1016/j.pmn.2012.02.001.

Wels, D. (2012). Management of postoperative pain. South African Family Practice, 54(3), 25-28. doi: 10.1080/20786204.2012.10874233

Wright, E.L., McGuiness, T., Moneyham, L.D., Schumacher, J.E., Zwerling, A., Stullenbarger N.E.N. (2012). Opioid abuse among nurse anesthetists and anesthesiologists. $A A N A$ Journal, 80(2), 120-128.

Yargıç, İ. (2009). Sağılı çalışanlanında bağımlılıkla ilgili sorunlar ve çözüm yollanı. Klinik Gelişim 22(4), 84-87. 